\title{
Territórios, Interculturalidade e Mediação: entre redes e nós
}

\author{
Territories, Interculturality and Mediation: between networks and knots
}

\author{
Ana Maria Costa e Silva*, Maria de Lurdes Carvalho** \\ *Instituto de Educação, CECS, Universidade do Minho, **Instituto de Educação, CIEC, Universidade do Minho
}

\begin{abstract}
Resumo
Esta comunicação enquadra-se num estudo em curso no âmbito de uma rede nacional em que participam o Alto Comissariado para as Migrações (ACM) e várias Instituições de Ensino Superior (IES) portuguesas, designada Rede de Ensino Superior em Mediação Intercultural (RESMI). Esta rede surge da constatação da importância da prossecução de políticas de apoio ao acolhimento e integração de migrantes, da promoção do diálogo entre diversas culturas, etnias e religiões e da necessidade de formação e investigação no âmbito da Mediação Intercultural.
\end{abstract}

\begin{abstract}
This communication is part of an under way study within a national network involving the High Commissioner for Migration (ACM) and several Portuguese higher education institutions (IES), designated Higher Education Network in Intercultural Mediation (RESMI). This network arises from the realization of the importance of keeping the policies that support the reception and integration of migrants, the promotion of dialogue between different cultures, ethnicities and religions and the need for training and research in the area of Intercultural Mediation.
\end{abstract}

Keywords: interculturality, mediation, public policies

\section{Introdução}

Os fluxos migratórios a nível mundial não são recentes, mas têm-se acentuado na última década por motivos vários, fundamentalmente políticos e religiosos, económicos, sociais e educativos. Estes movimentos trazem desafios políticos, culturais e sociais relacionados com a integração e inclusão de migrantes, que apelam ao diálogo intercultural e à gestão positiva da diversidade. Desde a década de 90 que Portugal tem vindo a acolher uma diversidade cultural, étnica e religiosa, com predomínio em áreas geográficas específicas que requerem uma intervenção concertada a nível territorial, como estratégia de gestão positiva da diversidade e coesão social. O reconhecimento da diversidade existente e da importância de promover a convivência intercultural tem constituído um objetivo das políticas públicas ao qual se associam instituições diversas quer ao nível da intervenção, quer da formação de profissionais com perfil adequado, dos quais se destacam os Mediadores Interculturais.

Neste texto far-se-á uma contextualização da mediação social e intercultural, tanto do ponto de vista teórico-concetual, como das práticas desenvolvidas em Portugal ao longo das últimas três décadas ao nível da intervenção social e da formação de mediadores sociais e interculturais. Incidir-se-á ainda no trabalho no âmbito da Mediação Intercultural em desenvolvimento por uma rede recentemente constituída - Rede de Ensino Superior em Mediação Intercultural (RESMI) - da qual fazem parte 24 instituições de ensino superior portuguesas e o Alto Comissariado para as Migrações (ACM). O enfoque principal centra-se na análise do papel da mediação e dos mediadores em territórios de multiculturalidade significativa, nomeadamente no desatar de nós dificultadores do diálogo e das relações interpessoais, com vista à facilitação e construção de laços e da coesão social.

\section{Gestão da diversidade, inclusão social e mediação intercultural}

Em Portugal, as práticas de mediação que têm como objetivo a inclusão social têm origem e estão associadas à crescente diversidade social e cultural, à democratização da educação, à necessidade e importância de elevar os níveis de inserção e integração escolar e de sucesso educativo, assim como de inserção social (Silva, 2014).

Esta realidade, com especial visibilidade a partir da década de 90 do século passado, leva ao desenvolvimento de experiências e de ações no sentido de contribuir para uma maior coesão e para um desenvolvimento social mais harmonioso, nomeadamente através da promoção de uma cultura de reconhecimento do outro, de participação e de cidadania responsável, apelando a práticas socioprofissionais que ocorrem na fronteira entre a comunidade, a escola e a família (Freire, 2010). São práticas que têm como principais objetivos a integração social e o combate à exclusão social, prevenindo o insucesso, o abandono escolar e percursos adversos e/ou criminais de crianças e jovens e gerindo litígios entre vizinhos, na comunidade e nos contextos escolares (Pedroso, Trincão \& Dias, 2001), procurando construir alternativas sociais.

Face à crise dos laços sociais (Lemaire \& Poitras, 2004), as práticas sociais de mediação promovem o reconhecimento do outro, a gestão da diferença e o restabelecimento dos laços sociais, conforme salientam Oliveira e Galego (2005, p. 24): 
"No sentido de poder proporcionar uma maior responsabilização individual, a mediação pode também proporcionar uma maior responsabilidade social, a qual é fundamental para o pleno exercício da cidadania. Esta particularidade revela-se particularmente útil, se pensarmos que esta pode ser utilizada como estratégia de intervenção junto daqueles que por circunstâncias várias (sociais, culturais, económicas, políticas, entre outras), se veem privados de certos bens e serviços essenciais, como a educação e a saúde, para a integração e coesão social. Aqui entramos no campo da chamada mediação social ou mediação sócio-cultural. Atualmente os países europeus apresentam dois fenómenos sociais que requerem também eles prementes soluções sociais. Um deles prende-se com as situações de exclusão social cada vez mais visíveis na sociedade. $\mathrm{O}$ outro tem a ver com as vagas de imigrantes de outros países da Europa, nomeadamente dos países de leste e de outros continentes. Estes fenómenos contribuem para a recomposição do tecido sócio-cultural desses países, que cada vez mais são multiculturais, onde a existência de códigos culturais distintos dificultam o acesso ao diálogo e fazem desencadear um conjunto de conflitos".

A mediação é um procedimento que privilegia a cooperação e a participação dos intervenientes (mediados) na procura de uma solução para os seus conflitos ou problemas, mutuamente satisfatória e potencialmente duradoura. Ao promover a participação na construção de soluções satisfatórias, promove simultaneamente a aprendizagem da cooperação e a construção dos laços sociais e da coesão social.

É com base nestes pressupostos que sustentam a mediação, enquanto processo e procedimentos assentes em princípios e métodos específicos, que vários autores a reconhecem como 'uma justiça doce' (Six, 1990), 'ateliers silenciosos de democracia' (Faget, 2010) ou 'pedagogia do laço social’ (Zabarel, 2007).

A mediação é um processo que supõe a existência de terceira(s) pessoa(s), orientada(s) por princípios de não intervenção ou de intervenção mínima, que coloca o poder de decisão nos intervenientes no processo, cria oportunidades comunicacionais entre estes, oportunidades que permitam a emergência de argumentações racionais e a construção de compromissos exequíveis e responsáveis. Foi sendo introduzida nos diversos países e continentes, como um procedimento de gestão positiva de conflitos e como um modo de regulação social, com uma dupla função: 'regular conflitos' e 'fazer sociedade' (Briant \& Palau, 1999). Neste sentido, a mediação visa promover o interesse e respeito pelo outro, a promoção do diálogo e da escuta ativa, o desenvolvimento de atitudes cooperativas, o reconhecimento dos valores próprios e dos outros, a valorização dos interesses e necessidades de cada pessoa, a promoção da autonomia e da responsabilidade, a resolução de conflitos de forma não violenta, a melhoria das relações interpessoais. Por isso, a mediação é uma forma de restituição dos laços sociais através da comunicação, tendo como condição o reconhecimento do outro (Zabatel, 2007).
A Mediação Intercultural, considerada como um enfoque específico transversal aos diferentes âmbitos da Mediação, é definida por Gimenez (1997, p. 142) assim: "Modalidade de intervenção de terceiras partes, em e sobre situações sociais de multiculturalidade significativa, orientada para a consecução do Reconhecimento do Outro e da aproximação das partes, a comunicação e a compreensão mútua, a aprendizagem e o desenvolvimento da convivência, a regulação de conflitos e adequação institucional, entre atores sociais ou institucionais etnoculturalmente diferenciados.”

Este enfoque da Mediação a nível internacional decorre precisamente da intensificação do contacto entre culturas num mundo globalizado, das migrações e do seu impacto sociocultural, do reconhecimento da presença de minorias étnicas autóctones e também da valorização e afirmação das identidades culturais.

Esta definição de Mediação Intercultural levará a identificar e clarificar conceitos, muitas vezes usados de forma equivalente, nomeadamente os conceitos de multiculturalidade e interculturalidade. Todavia, esta reflexão ultrapassa os objetivos deste texto, sublinhando-se, no entanto, que se considera a interculturalidade como o grau máximo de relações entre culturas, de modo que chega a ser uma integração global dentro de um sistema social, que explica a realidade sem fragmentações. Esta relação mútua e interdependente é permeabilizada por um "conhecimento" do outro, "reconhecendo-o" e valorizando-o através de processos de comunicação e compreensão mútua (Giménez, 1997). Ainda na linha de pensamento de Giménez, e numa perspetiva humanista e social, o reconhecimento do outro exige: i) o reconhecimento do seu Eu diferenciado; ii) processos de relação com o outro, de comunicação, reconhecimento, compreensão e convivência; iii) construção da visão de mundo pessoal e social aberta à diversidade.

Em síntese, a mediação em geral e também a mediação intercultural promove as relações cooperativas, seja a nível preventivo, seja a nível resolutivo de conflitos já instalados; facilita a comunicação e a descoberta participada de soluções; recria a instância de diálogo; reforça as possibilidades de recuperar e reinstalar recursos relacionados com o aumento da socialização, com o desenvolvimento de padrões de colaboração, com o reconhecimento do outro e com a responsabilidade individual e social. A participação das pessoas de forma voluntária é uma condição essencial para o exercício da mediação e para promover o diálogo, a aprendizagem cooperativa e a construção dos laços sociais.

\section{Mediação social e intercultural em Portugal: intervenção e formação}

Ao longo dos últimos 30 anos as práticas de Mediação Social e Intercultural em Portugal estão associadas a projetos e programas diversos com incidência em contextos de diversidade cultural significativa, concretamente em contextos socioeducativos, escolares e comunitários. São programas com financiamentos públicos e privados, alguns deles mantidos, potenciados e alargados em extensão geográfica e número de projetos 
envolvidos; outros têm vindo a ser implementados mais recentemente, como expressão da necessidade e do interesse pelas práticas de Mediação.

As primeiras iniciativas de mediação para a inclusão social foram levadas a cabo por instituições e associações privadas e organizações não governamentais, nomeadamente a Pastoral Social dos Ciganos, a Associação Cultural Moinho da Juventude e o Instituto das Comunidades Educativas. Paralelamente, surgem iniciativas autónomas e de apoio por parte de diversos órgãos e/ou figuras governamentais (Ministros e Ministérios da Educação, da Presidência, da Segurança Social, entre outros), dando origem a Programas e Projetos da iniciativa de um ou de vários desses Ministérios: por exemplo, o Programa TEIP e o Programa Escolhas que tendo início no final da década de 90 e no início da década de 2000, se têm reeditado e atualizado até à atualidade. Estes dois Programas contam com o apoio financeiro dos Ministérios da Educação e da Segurança Social e verbas dos programas estruturais da Comunidade Europeia. São experiências, projetos e programas que contam com o trabalho em rede, a participação e o patrocínio de diversas estruturas, instituições e organizações, com frequência autarquias, escolas, serviços locais da Segurança Social, Associações Sociais e Culturais, entre outras.

Identificam-se, em seguida, alguns destes programas e projetos e a sua distribuição geográfica em Portugal.

Entre 1993 e 1997 foi implementado o Projeto de Educação Multicultural. Foi um projeto regional, concentrado em Lisboa e Vale do Tejo. Incidia numa intervenção preventiva nas escolas com heterogeneidade cultural, de modo a potenciar condições para prevenir o insucesso e abandono escolar e a exclusão social.

Desde 1996 até hoje existe o Programa TEIP (Territórios Educativos de Intervenção Prioritária), atualmente na $3^{\text {a }}$ edição. Este Programa tem implementação nacional (continente e ilhas) sob a responsabilidade do Ministério da Educação. Tem subjacente uma filosofia de descriminação positiva para as escolas e populações mais carenciadas, dando prioridade à escola básica e à igualdade de oportunidades.

Em 2001 foi lançado o Programa Escolhas a nível nacional. Este Programa, criado pela Presidência do Conselho de Ministros e integrado no Alto Comissariado para as Migrações, tem como missão promover a inclusão social de crianças e jovens de contextos socioeconómicos vulneráveis, visando a igualdade de oportunidades e o reforço da coesão social. Atualmente, na sua $5^{\text {a }}$ geração, mantém protocolos com os consórcios de 110 projetos locais de inclusão social em diversas comunidades e muitos deles incidem em territórios onde se concentram descendentes de imigrantes e minorias étnicas.

A partir de 2009 foi criado o Projeto de Mediadores Municipais. Este Projeto de âmbito nacional foi criado pelo Alto Comissariado para a Imigração e Diálogo Intercultural (ACIDI, atualmente ACM). Tem como objetivos fundamentais melhorar $\mathrm{o}$ acesso das comunidades ciganas a serviços e equipamentos locais e promover a comunicação entre a comunidade cigana e a comunidade envolvente com vista à prevenção e gestão de conflitos.

Também a partir de 2009 surge o Projeto de Mediação Intercultural em Serviços Públicos (MISP). É promovido pelo Alto Comissariado para as Migrações (ACM), em parceria com Câmaras Municipais e Associações de Imigrantes, cofinanciado pelo Fundo Europeu para a Integração de Nacionais de Países Terceiros (FEINPT). É um projeto de mediação intercultural com enfoque comunitário, contando com a colaboração dos serviços públicos e privados.

O ACM tem sido o promotor de programas diversos e parcerias interinstitucionais: são disso exemplo o programa Escolhas, o programa de Mediadores Municipais e o programa Mediação Intercultural em Serviços Públicos (MISP).

A implementação e consolidação destes programas, bem como a complexidade da intervenção social que lhe está associada, exigiu e continua a exigir profissionais com formação adequada e especializada.

Em Portugal, a formação específica de mediadores socioculturais teve início em meados da década de 90, por iniciativa de instituições privadas: da Associação Cultural Moinho da Juventude, do Instituto de Apoio à Criança, do Centro Nacional de Apoio ao Imigrante e de Promoção Social dos Ciganos e no âmbito de Programas específicos como o Programa Escolhas, o Programa TEIP e pelas próprias entidades que acolhem os mediadores.

Ao longo da $1^{\text {a }}$ década do séc. XXI, foram sendo implementadas diferentes formações, na sua maioria dispersas e sem regularidade, por algumas instituições de Ensino Superior Público e Privado, e por outras organizações públicas e privadas, como a Associação Desenvolvimento Integrado de Matosinhos (ADEIMA), o Centro Português para os Refugiados e o Alto Comissariado para a Imigração e o Diálogo Intercultural (ACIDI/ACM).

Atualmente são várias as Instituições de Ensino Superior portuguesas que promovem oferta educativa no âmbito da Mediação Social e Intercultural. Relativamente à formação, verifica-se uma diversidade de oferta, assim como a existência de pouca homogeneidade e unidade a nível formativo. Embora se encontrem eixos comuns em áreas temáticas, as modalidades, duração, acreditação, destinatários são muito diversas.

Existe, ao nível da maior parte das formações, um défice de temáticas específicas de mediação e prática, nomeadamente ao nível dos princípios, dos modelos e das técnicas. Em dois estudos realizados em Portugal (Oliveira \& Galego, 2005; Silva et al., 2010), os mediadores reconhecem a importância da formação realizada para o desempenho das funções, mas referem a necessidade de mais formação especializada e de espaços de reflexão e intercâmbio.

\section{Rede de Ensino Superior em Mediação Intercultural: os nós da rede}

A RESMI surge, em grande medida, do encontro de interesses e desafios comuns com a missão do Alto Comissariado para as Migrações e de um conjunto de 
Instituições de Ensino Superior com responsabilidades, quer ao nível do financiamento e supervisão da implementação de projetos no terreno, quer ao nível da formação especializada, investigação e acompanhamento de projetos de intervenção em Mediação Social e Intercultural.

Neste sentido, a RESMI, para além de ser uma iniciativa em rede do ACM com IES, é também, e fundamentalmente, uma mobilização do ensino superior e do ACM que se liga a iniciativas e organizações de base territorial local, regional, nacional e internacional. Esta mobilização traduz-se, na prática, em parcerias com comunidades locais e com os seus projetos de interculturalidade, bem como no desenvolvimento de investigação e formação que os possa apoiar e sustentar. A rede a que se vem referindo, foi formalmente constituída através da assinatura de uma Carta de Compromisso comum, em maio de 2015, e organiza-se em quatro grupos de trabalho: i) Educação; ii) Sáude; iii) Território; iv) Monitorização das práticas de mediação intercultural em contexto comunitário.

As autoras deste texto integram o grupo trabalho (GT) Território, pelo que se incide aqui nos objetivos e estratégias em curso deste grupo.

O GT Território tem uma representação nacional, com IES do norte, centro e sul do país, nomeadamente: Universidade do Minho, Universidade Aberta e Universidade Lusófona do Porto, Instituto Politécnico e Escola Superior Paula Frassinetti do Porto, Universidade de Aveiro, Institutos Politécnicos da Guarda, Castelo Branco e Beja.

Este GT constitui-se como uma comunidade de prática e de aprendizagem. As comunidades de prática e de aprendizagem caraterizam-se pela circularidade de saberes (Martinand citado em Burguiere, 2002) que são, ao mesmo tempo, lugares de produção de saberes, sem hierarquização entre si, mantendo as diferenças concretas e reais em cada processo de circulação. Enfrenta-se aqui a ideia de "entre-lugares" de Bhabha (2008, p. 20), segundo a qual "é na emergência dos interstícios - a sobreposição e o deslocamento de domínios da diferença - que as experiências intersubjetivas e coletivas (...), o interesse comunitário ou o valor cultural são negociados”. A circularidade ‘entre-lugares’ pressupõe em si mesma a ideia de movimento pendular, de dinâmicas nos saberes que dialogam e se transformam, entre a comunidade académica e as comunidades locais. Para além de ser uma comunidade de prática, o GT Território pretende construir saberes que consolidam os nós da rede. Acredita-se que esta circularidade de saberes promove a criação de redes entre as comunidades académicas e os territórios/comunidades locais, ocupando a mediação intercultural os nós entre as instituições e os saberes.

Enquanto comunidade de aprendizagem, cada um dos membros do GT começou por identificar as suas motivações e interesses de pertença ao grupo tendo sido sistematizados em seis aspetos principais: 1) perspetivar o território enquanto espaço privilegiado para a mediação intercultural; 2) potenciar as redes locais de interação das Instituições de Ensino Superior com a Comunidade Local (território) através de um conhecimento e reconhecimento das dinâmicas e experiências locais no âmbito da diversidade cultural; 3) potenciar os saberes e experiências dos elementos do GT e o seu intercâmbio em torno da reflexão e formação em Mediação Intercultural; 4) partilhar com a comunidade local saberes e práticas de mediação intercultural; 5) desenvolver metodologias participativas de pesquisa e trabalho com as comunidades e grupos de migrantes; 6) apoiar os Mediadores nos serviços públicos e Associações privadas e não-governamentais.

Enquanto comunidade de prática e de aprendizagem, o GT começou por construir e concetualizar a noção de território num debate alargado entre os elementos do projeto. Sendo certo que a noção de território é, simultaneamente, uma construção pessoal e social, e consequentemente caraterizado pela sua polissemia e complexidade, ela tem de ser problematizada enquanto espaço material e geográfico mas também enquanto construção simbólica.

Tal como refere Ferreira (2014, p. 113) "mais do que traduzir "o que é" ou "o ser” do território, trata-se de discutir o seu devir, isto é, em que problemática nos envolvemos ou que questões práticas acionamos a partir dos conceitos de territórios e territorialidade academicamente construídos”.

Também Haesbaert (2004a, p. 95) adverte sobre o conceito de ‘território usado' que "constitui-se como um todo complexo onde se tece uma trama de relações complementares e conflituantes. Daí a vigor do conceito convidando a pensar processualmente as relações estabelecidas entre o lugar, a formação socioespacial e o mundo" (Haesbaert 2004a, p. 95). Para este autor, o território como espaço abarca mais do que o estritamente natural, unicamente político, econômico ou cultural, pelo que deve ser concetualizado numa geografia integradora entre as diferentes dimensões humanas e sociais. Nesta geografia integradora as forças de poder e de apropriação, de funcionalidade (recurso) e de identidade (símbolo) assumem intensidades iguais ou próximas de tal forma que Bonnemaison e Cambrèzy (1996, citados em Haesbaert 2004b, p.4) referem que "perder seu território é desaparecer", ou seja, o território "não diz respeito apenas à função ou ao ter, mas ao ser”.

Assim, o território é um conceito sensível da mediação intercultural não apenas enquanto espaço geográfico, mas igualmente enquanto comunidade imaginada e significado subjetivo.

Pede-se à mediação em geral e à mediação intercultural em particular que contribua para a promoção dos laços e da coesão social, para a melhoria da qualidade de vida e para a convivência cidadã que promova uma gestão positiva e preventiva da diversidade.

Um desafio que se coloca ao grupo de trabalho é traduzir na prática aquilo que sabe teoricamente.

Nem sempre é fácil convocar o outro, os outros, diferentes, com experiências, representações e histórias singulares, muitas vezes de privação, de discriminação, de marginalização. O seu modo de comunicar valores, representações, sentidos e prioridades podem não ser colaborativos ou dialógicos. Às vezes são antagónicos, conflituosos e incomensuráveis. Construir e potenciar redes de comunicação e consolidar nós de compreensão 
mútua, de reconhecimento do Outro e de aprendizagem e o desenvolvimento da convivência é um grande desafio que se nos coloca. Um outro desafio corresponde ao que sabemos sobre a representação da diferença, que não pode ser conseguida exclusivamente a partir de traços culturais e étnicos pré-definidos. Trata-se de uma articulação social, complexa, decorrente de afiliações específicas em momentos específicos.

\section{Referências}

Bhabha, H. K. (1998). O local da cultura. Belo Horizonte: Ed. UFMG.

Burguiere, E. (2002). Entretien avec Jean-Louis Martinand. Recherche et Formation, 40, 87-94.

Briant, V. \& Palau, Y. (1999). La médiation: définition, pratiques et perspectives. Paris: Nathan Univérsité.

Corbo Zabatel, E. (2007). Breve ensayo sobre lo posible. In R. B. Frigerio \& G. Diker (eds), Las formas de lo escolar. Buenos Aires: Del Estante Editorial.

Faget, J. (2010). Médiations, les ateliers silencieux de la démocratie. Paris: Eres.

Ferreira, D. S. (2014). Território, territorialidade e seus múltiplos enfoques na ciência geográfica. CAMPO-TERRITÓRIO: revista de geografia agrária, v. 9, n. 17, 111-135.

Freire, I. (2010). Mediação em Educação em Portugal. In J. A. Correia \& A. M. Silva (orgs.). Mediação:(d)os contextos e (d)os actores (pp. 59-70). Porto: Edições Afrontamento.

Fritz, J.-M. (2004). Derrière la magie: Modèles, approches et théories de médiation. Esprit Critique, 6(3). Disponível em http://www.espritcritique.fr/0603/esp0603article01.pdf, consultado em 12 de maio de 2015.
Giménez, C. (1997). La naturaleza de la mediación intercultural. Revista de Migraciones 2, 125-159.

Haesbart, R. (2004a). O Mito da Desterritorialização: do "fim dos territórios" à multiterriotorialidade. Rio de Janeiro: Bertrand Brasil.

Haesbaert, R. (2004b). Dos múltiplos territórios à multiterritorialidade. Disponível online em http://www.ufrgs.br/petgea/Artigo/rh.pdf.

Lemaire, E. \& Poitras, J. (2004). La construction des rapports sociaux comme l'un des objectifs des dispositifs de médiation. Esprit Critique, nº6, 17-29.

Oliveira, A. \& Galego, C. (2005). A Mediação Sócio-Cultural: um puzzle em construção. Lisboa: ACIDI.

Pedroso, J., Trincão, C. \& Dias, J. P. (2001). Percursos da informalização e da desjudicialização - por caminhos da reforma da administração da justiça (análise comparada). Coimbra: Observatório Permanente da Justiça Portuguesa/CES.

Silva, A. M. C. (2014). Estado atual da investigação e das práticas em Mediação para a Inclusão Social (MIS) em Portugal. Relatório elaborado no âmbito do Projeto ArleKin Formation à la médiation pour l'inclusion sociale par la mobilité européenne. Référence: 539947-LLP-1-2013-1-FR-GRUNDTVIG-GMP.

(Janeiro, não publicado).

Silva, A. M., Caetano, A. P., Freire, I., Moreira, M. A., Freire, T \& Ferreira, A. S. (2010). Novos actores no trabalho em educação: os mediadores socioeducativos. Revista Portuguesa de Educação, 23 (2), 119-151.

Six, J.-F. (1990). Le Temps des Médiateurs. Paris: Éditions du Seuil. 